\title{
Bond University
}

\section{Legal Education Review}

Volume 28 Issue 1

2018

Do (Underperforming) Students Benefit from a Flipped Lecture? Evidence from Business Students Studying Company Law

Felix E Mezzanotte

Hong Kong Polytechnic University

Follow this and additional works at: https://ler.scholasticahq.com/

Licence. 


\title{
DO (UNDERPERFORMING) STUDENTS BENEFIT FROM A FLIPPED LECTURE? EVIDENCE FROM BUSINESS STUDENTS STUDYING COMPANY LAW
}

\author{
FÉLIX E MEZZANOTTE*
}

\section{INTRODUCTION}

In this article findings are reported from a project that flipped the traditional face-to-face lecture in a course of company law at the School of Accounting and Finance of the Hong Kong Polytechnic University. In this course, the curriculum has relied on the traditional mode of teaching consisting of a one-hour face-to-face lecture (to a large-size class of nearly 200 students) followed, later in the week, by two-hour seminar classes (organised in smaller groups of approximately 30 students). The purpose of the weekly lecture has been to transfer basic knowledge that the students later integrate in seminar classes through problem-solving and critical-thinking activities. However, knowledge transfer by means of face-to-face lectures has underperformed, particularly because accounting and finance students — largely unfamiliar with law studies — have struggled to assimilate the complex legal terms, principles and rules which are essential to company law. Consequently, after the lecture is over a high percentage of our students sit in the subsequent seminar classes ill-prepared, with negative effects on their learning and performance. ${ }^{1}$

With the purpose of improving students' preparation for seminar classes, a project was implemented in the spring semester 2016/17 by which an innovation, the 'flipped lecture', was introduced in replacement of the face-to-face lecture. The flipped lecture consisted

\footnotetext{
School of Accounting and Finance, Hong Kong Polytechnic University.

Problems of students' unpreparedness have been documented in relation to law courses for non-law students, see Fritz Ewang, 'Teaching Law to Accounting and Business Students: A Cumulative Dual Model' (2008) 5(2) Journal of University Teaching and Learning Practice 16, 16-17; Susan Douglas, 'Student Engagement, Problem Based Learning and Teaching Law to Business Students' (2012) 6(1) EJournal of Business Education and Scholarship of Teaching 33, 37-8; Vida Allen, 'A Critical Reflection on the Methodology of Teaching Law to Non-Law Students' [2007] (4) Web Journal of Current Legal Issues; Susanna C Monseau, 'MultiLayered Assignments for Teaching the Complexity of Law to Business Students' (2005) 17 International Journal of Case Method Research and Application 531, 533-4.
} 
of three different tasks: (1) a set of three five-minutes, pre-recorded videos that narrated the lecture slides; (2) an online graded quiz; and (3) a fifty-minute face-to-face feedback session in the lecture theatre for all the students. Out of a total of twelve lectures in the semester, two lectures were flipped whereas the rest of the lectures remained as face-to-face. Flipping no more than two lectures allowed our team to pilot this new teaching method while meeting the project's limited resources. Since our school has not yet implemented a general policy in relation to video-lectures or blended learning, there was ample leeway for project design. A single cohort of students $(n=190)$ were asked whether they preferred the flipped over the traditional lecture, and whether they felt that the flipped lecture prepared them better to engage in seminar activities.

Results from survey data showed that, on average, there was only a slight difference in preference and preparedness in favour of the flipped lecture. This difference, however, turned out to be larger and statistically significant when the sample was split by student GPA (grade point average) scores. Relative to High-GPA students, LowGPA students liked the flipped lectures more and felt better prepared to work in seminar classes. This result was even stronger for the group of Low-GPA students who had watched the pre-recorded videos at least twice. This pattern was also observed when analysing data obtained from the students' final exam grades. Although one exam question had been taught by means of the flipped lecture and another question by means of the traditional lecture, High-GPA students obtained the same grade in both questions, whereas Low-GPA students obtained significantly higher grades in the flipped lecture question. All these elements indicate that the flipped lecture proved more beneficial to the group of students who needed greater support in learning.

The most positive aspect of the flipped lecture cited by the students in the survey was their ability to stop and play again the prerecorded videos along with the perceived boost in learning resulting from this possibility in terms of greater clarity and understanding of the lecture topic. In the following sections of this article the design of the flipped lecture will be described and the project's findings reported.

\section{ELEMENTS OF THE FLIPPED LECTURE}

Diverse ways of using pre-recorded videos in lecturing have been studied in the literature. In some studies, the video-lecture functioned as a perfect substitute for the traditional lecture: the students were allocated to either watch the video-lecture or attend a traditional, live lecture. Examples of this use of videos for lecturing are found in the work of, among others, Schreiber, Fukuta and Gordon, ${ }^{2} \mathrm{Lu}$ and

\footnotetext{
Benjamin E Schreiber, Junaid Fukuta and Fabiana Gordon, 'Live Lecture Versus Video Podcast in Undergraduate Medical Education: A Randomised Controlled Trial' (2010) 10 BMC Medical Education 68.
} 
Lemonde, ${ }^{3}$ DiRienzo and Lilly, ${ }^{4}$ and Bahnson and Olejnikova. ${ }^{5}$ In other studies, such as Wieling and Hofman, ${ }^{6}$ Gorissen, van Bruggen and Jochems, ${ }^{7}$ and Le et $a l,{ }^{8}$ the videos contained a full record of the face-to-face lecture. In this situation, the video-lecture worked as a complement of the face-to-face lecture. The students would use the pre-recorded videos to watch again the content of the live lecture or, for the case of absentee students, watch it for the very first time.

Video-lectures have also been used as part of the flipped classroom teaching method. Here, the content of the lecture is narrated and pre-recorded in videos that are watched by the students prior to and outside the class. This twist frees up in-class time which is utilised, instead of lecturing, to engage the students in deep-learning activities. ${ }^{9}$ Unlike the video-lectures described in the previous paragraph, in the flipped classroom the video neither substitutes nor complements the live lecture. The lecture is delivered outside the classroom, with class time being utilised to meet higher learning objectives. A number of articles published by Threedy and Dewald, ${ }^{10}$ Wangerin ${ }^{11}$ and Landrum, ${ }^{12}$ among others, have fostered the use of the flipped classroom in law schools. They have suggested that basic cognitive skills (knowledge and comprehension) be conveyed to law students online by means of pre-recorded videos while preserving inclass time to train those students in problem-solving and other higher cognitive skills.

The design of our project was inspired by the flipped classroom model to the extent that the lecture was moved outside the class (video-lectures) while the in-class time left available was filled in with

3 Fletcher Lu and Manon Lemonde, 'A Comparison of Online Versus Face-to-Face Teaching Delivery in Statistics Instruction for Undergraduate Health Science Students' (2013) 18 Advances in Health Science Education 963.

4 Cassandra DiRienzo and Gregory Lilly, 'Online Versus Face-to-Face: Does Delivery Method Matter for Undergraduate Business School Learning’ (2014) 6(1) Business Education and Accreditation 1.

5 Jane Bahnson and Lucie Olejnikova, 'Are Recorded Lectures Better than Live Lectures for Teaching Students Legal Research' (2007) 109 Law Library Journal 187.

6 M B Wieling and W H A Hofman, 'The Impact of Online Video Lecture Recordings and Automated Feedback on Student Performance' (2010) 54 Computers and Education 992.

7 Pierre Gorissen, Jan van Bruggen and Wim Jochems, 'Students and Recorded Lectures: Survey on Current Use and Demands for Higher Education' (2012) 20 Research in Learning Technology 297.

8 Ada Le et al, 'Online Lecture Accessibility and its Influence on Performance in Skills-Based Courses’ (2010) 55 Computers and Education 313.

9 Jacob Lowell Bishop and Matthew A Verleger, 'The Flipped Classroom: A Survey of the Research' (Paper presented at the $120^{\text {th }}$ ASEE Annual Conference and Exposition, Atlanta, 23 June 2013).

10 Debora L Threedy and Aaron Dewald, 'Re-Conceptualizing Doctrinal Teaching: Blending Online Videos with In-Class Problem-Solving' (2015) 64 Journal of Legal Education 605.

11 Paul Wangerin, 'Technology in the Service of Tradition: Electronic Lectures and Live-Class Teaching' (2003) 53 Journal of Legal Education 213.

12 Susan D Landrum, 'Drawing Inspiration from the Flipped Classroom Model: An Integrated Approach to Academic Support for the Academically Underprepared Law Student' (2015) 53 Duquesne Law Review 245. 
complementary activities. More specifically, per each flipped lecture, three short-duration videos (about five minutes per video) were recorded in advance, installed with the assistance of IT experts in the Blackboard Learning Management System (Blackboard) and displayed as YouTube videos. The videos narrated and displayed the usual Power Point lecture slides that would have otherwise been delivered in the face-to-face lecture for the weekly topic. The videolecture was designed to be an outside-class activity and, therefore, its content was not delivered again in class. The same lecturer narrated the video-lectures and delivered the face-to-face weekly lectures covering the rest of the course topics in the semester.

In each flipped lecture, the students were asked to watch the videolecture and, following that, complete a quiz composed of twelve multiple choice questions (MCQs). Those MCQs asked the students to select the correct answer among four optional answers. In some MCQs, the students were asked to answer either true or false. The quiz was graded, open-book, completed outside class and operated online through Blackboard. The quiz completion period opened and closed automatically and gave the students about four days to finish the task. Working on the quiz demanded that the students watch the videolecture attentively. Since not all the answers to the MCQs could be drawn from the videos, the students were also instructed to read the course textbook in order to complete the quiz. An automated feedback function built-in Blackboard and applicable to each MCQ was added. Through this function the students gained access to written feedback online immediately after the quiz's deadline had passed.

The video-lecture and the quiz were designed to free up the onehour time slot originally occupied by the live lecture. That hour was used by the lecturer to provide the class with an extra session of faceto-face feedback on the key concepts addressed by the MCQs and their answers.

Put together, the video-lecture, the online quiz and the live feedback session constituted the flipped lecture. It was expected that the flipped lecture, compared with the traditional lecture, would help our students better acquire the basic knowledge and comprehension of the lecture topic, and thereby, learn higher cognitive skills - largely the application of the law to resolve problems - more effectively in the two-hour seminar class that follows the lecture. The flipped lecture was evaluated by comparison with the traditional lecture in terms of the students' (1) preferences, (2) preparedness and (3) performance. The findings from the student survey's responses and the analysis of assessment grades are presented and discussed in the following sections of this article. ${ }^{13}$

13 The author has approval to use, analyse and publish the data exhibited in this article. 


\section{RESUlTS FROM THE STUDENT SURVEY: CLOSED-ENDED QUESTIONS}

A project assistant administered a paper survey to a single cohort of students $(n=190)$ across seminar classes in the ninth teaching week. The survey was responded voluntarily and anonymously by 58 per cent of the students registered for the course. Among the respondents, the use of the pre-recorded videos was very high. As shown in Table 1, roughly 89 per cent of the students stated that they had watched all the videos for each flipped lecture, and 78 per cent played the videos at least twice. Although all the respondents completed the quiz online, only 73.6 per cent of them attended the ensuing feedback session on the solutions to the quiz.

Table 1

Use of Pre-recorded Videos and Feedback Session Attendance

\begin{tabular}{|c|c|c|c|}
\hline \multicolumn{4}{|c|}{ Number of respondents watching the pre-recorded videos } \\
\hline $\begin{array}{l}\text { Total no. } \\
\text { respondents }\end{array}$ & $\begin{array}{l}\text { Videos covering } \\
\text { the two flipped } \\
\text { lectures }\end{array}$ & $\begin{array}{l}\text { Videos covering } \\
\text { one flipped } \\
\text { lecture only }\end{array}$ & $\begin{array}{l}\text { Watched } 0 \\
\text { videos }\end{array}$ \\
\hline $110(100 \%)$ & $98(89.1 \%)$ & $10(9.1 \%)$ & $2(1.8 \%)$ \\
\hline \multicolumn{4}{|c|}{$\begin{array}{l}\text { Number of respondents watching the pre-recorded videos one or more } \\
\text { times }\end{array}$} \\
\hline $\begin{array}{l}\text { Total no. } \\
\text { respondents }\end{array}$ & 1 time & $\begin{array}{l}\text { More than } 1 \\
\text { time }\end{array}$ & \\
\hline $108(100 \%)$ & $24(22.2 \%)$ & $84(77.8 \%)$ & \\
\hline \multicolumn{4}{|c|}{ Number of respondents attending the live feedback sessions } \\
\hline $\begin{array}{l}\text { Total no. } \\
\text { respondents }\end{array}$ & 2 sessions & 1 session & 0 sessions \\
\hline $110(100 \%)$ & $81(73.6 \%)$ & $15(13.6 \%)$ & $14(12.7 \%)$ \\
\hline
\end{tabular}

The survey questions asked the students to make the following comparisons: (a) how much they liked the flipped lecture compared with the traditional lecture (variable: Preference); and (b) how well the flipped lecture prepared the students for seminar activities compared with the traditional lecture (variable: Preparedness). These two questions were closed-ended and used a 5-point Likert scale, as follows: 1 (Much Worse), 2 (Worse), 3 (Same), 4 (Better) and 5 (Much Better). The students were also given the choice to tick a zero scale option if they were not sure about their response. As an additional metric, the students were asked to score from 1 to 10 points the flipped lecture (variable: FL_Score) and, in a separate question, the traditional lecture (variable: TL_Score). Similarly, students gave a score, from 1 to 10 points, for the video component of the flipped 
lecture (variable: Video_Score) and, separately, the quiz component which was defined to include both the online MCQs and the live feedback session (variable: MCQs_Score). The students were also asked to state their age, gender and GPA scores at the time of course registration (variables: Age, Gender and GPA_Survey). ${ }^{14}$

Nonparametric tests in the Stata statistical program were used to conduct equality tests and p-values were reported. The Wilcoxon signed-rank test was utilised to make diverse comparisons between ordinal variables (comparisons between FL_Score and TL_Score, and between Video_Score and MCQs_Score). The Kruskal-Wallis H test was utilised to understand whether a dependent - continuous or ordinal — variable (eg Preference, Preparedness and FL_Score, among other variables) differed based on gender, age or GPA-score groups (independent variables: Gender, Age and GPA scores)

Summary statistics are presented in Table 2. The flipped lecture was preferred over the traditional lecture by a very slight margin (mean $=3.373)$. A similar outcome arose in relation to preparedness (mean $=3.523)$. Consistently, when the respondents were asked to give a score from 1 to 10, the flipped lecture scored slightly higher than the traditional lecture yet without achieving statistical significance $(6.639>6.370 ; \mathrm{p}$-value $=0.119)$.

Table 2

Summary Statistics from Survey Data

\begin{tabular}{|l|c|c|c|c|c|}
\hline $\begin{array}{l}\text { Variables } \\
\text { from Survey }\end{array}$ & Obs & Mean & Std Dev & Min & Max \\
\hline Preference & 99 & 3.373 & 1.225 & 1 & 5 \\
\hline Preparedness & 107 & 3.523 & 0.955 & 1 & 5 \\
\hline FL_Score & 108 & 6.639 & 2.177 & 1 & 10 \\
\hline TL_Score & 108 & 6.370 & 1.68 & 1 & 10 \\
\hline Video_Score & 108 & 6.639 & 2.202 & 1 & 10 \\
\hline MCQs_Score & 108 & 6.074 & 2.282 & 1 & 10 \\
\hline Gender & 105 & 0.505 & 0.502 & 0 & 1 \\
\hline Age & 108 & 21.11 & 1.089 & 19 & 24 \\
\hline GPA_Survey & 97 & 3.172 & 0.349 & 1.5 & 3.9 \\
\hline
\end{tabular}

On average, it could hardly be said that the flipped and traditional lectures created dissimilar perceptions among the students in terms of likeness and preparedness. As shown in Table 3, these outcomes did not change when the sample was split by gender or age. However, the respondents' GPA score proved to be a relevant factor. When the sample was broken down by the group of respondents having HighGPA (students with GPA_Survey above the average 3.172) and the

14 For reasons of cultural sensitivity, students were not asked to state their ethnicity. All students were undergraduate full-time students. These students were all taught using the same mode of delivery. 
group of respondents having Low-GPA (students with GPA_Survey equal or below the average 3.172), statistically significant differences emerged in relation to Preference, Preparedness and the score variables.

Compared with the group of High-GPA students, the group of Low-GPA students perceived that the flipped lecture was more likeable, and prepared them better for the subsequent seminar activities, than the traditional lecture. Moreover, the group of LowGPA students scored the flipped lecture significantly higher than they scored the traditional lecture $\left(\mathrm{FL} \_S c o r e=7.318>\right.$ TL_Score $=6.136$ p-value $=0.002$ ) and significantly higher than how the High-GPA students scored the flipped lecture $($ FL_Score $=7.318>$ FL_Score $=$ $6.321 \mathrm{p}$-value $=0.019)$. In contrast, it cannot be said that the group of High-GPA students scored the flipped and traditional lecture differently $($ FL_Score $=6.321<$ TL_Score $=6.528$ p-value $=0.979)$. All these results suggest that the weaker students in terms of GPA profited more from the flipped lecture.

\section{Table 3}

Students' Perceptions Broken Down by Gender, Age and GPA Score

See next page. 


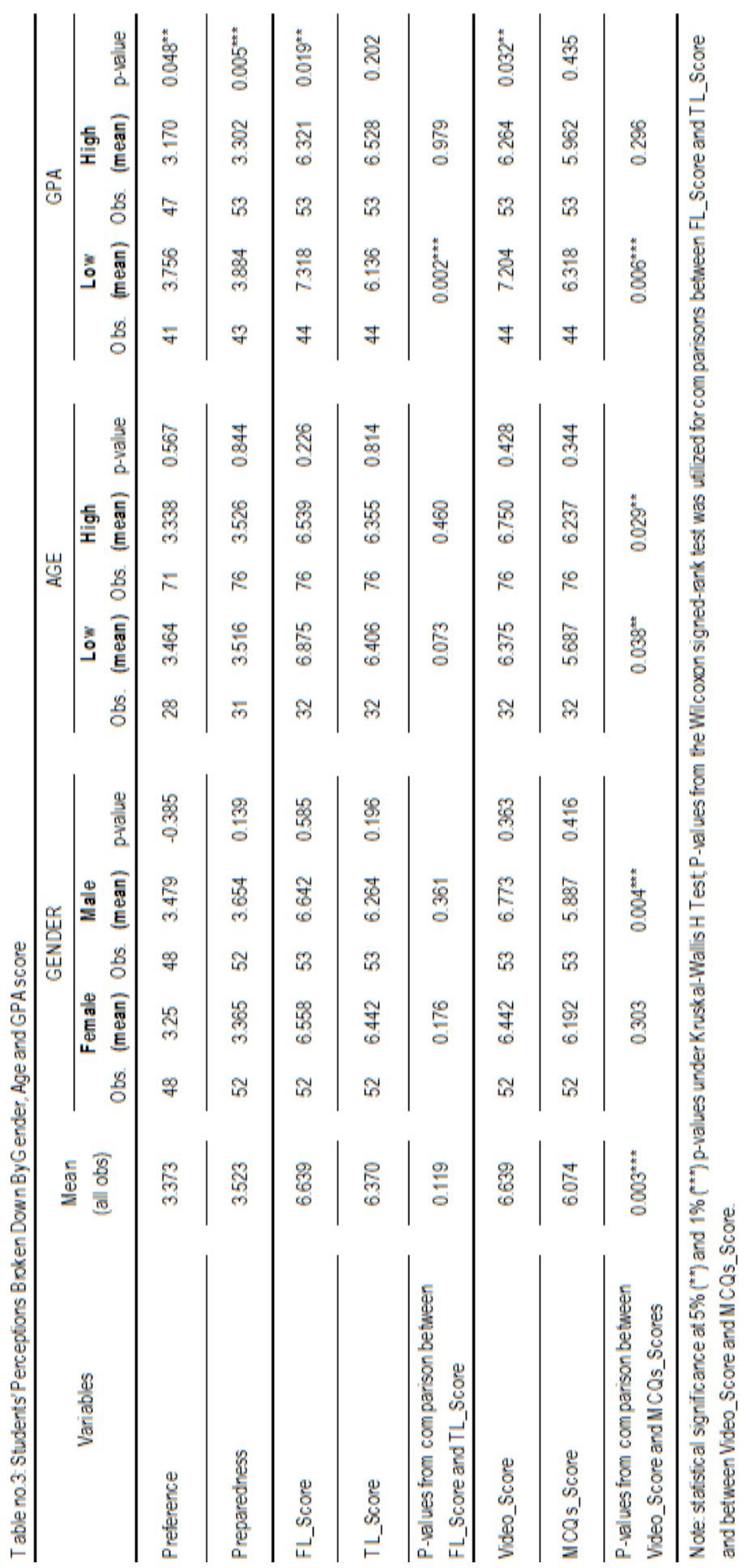


Low_GPA students rated the video component of the flipped lecture higher than High_GPA students did (Video_Score $=7.204>$ Video_Score $=6.264 \mathrm{p}$ value $=0.032$ ). Low_GPA students also perceived the video as the most important component of the flipped lecture rating it significantly higher than the quiz component (Video_Score $=7.204>$ MCQs_Score $=6.318$ p-value $=0.006$ ), whereas it cannot be said that High_GPA students ranked the video and the quiz differently (Video_Score $=6.264>$ MCQs_Score $=5.962$ p-value $=0.296$ )

The groups of Low-GPA students and High-GPA students were split into subgroups of students who watched the videos only once and those students who watched the videos more than once. In this scenario, the difference in FL_Score and TL_Score were not statistically significant in all the subgroups except for the subgroup of Low-GPA students who watched the videos multiple times. On average, this subgroup exhibited the highest score differential found in our sample $($ FL_Score $=7.411>$ TL_Score $=6.056 \mathrm{p}$-value $=0.001)$, suggesting that the flipped lecture, relative to the traditional lecture, benefited the most those students with Low-GPA who watched the videos at least twice.

More generally, the comparison between the mean of Video_Score (6.639) and of MCQs_Score (6.074) shows that the video component of the flipped lecture played a greater role in forming positive perceptions of the flipped lecture. With the data from our survey, however, it cannot be ascertained whether the online MCQs or the subsequent live feedback session provided a stronger reason for the lower magnitude in MCQs_Score. As it will emerge from the next section of this article, however, students cited a few MCQs-related problems as weaknesses of the flipped lecture.

\section{RESULTS FROM THE STUDENT SURVEY: OPEN-ENDED QUESTIONS}

One open-ended question was included in the survey. Survey question no 4 first asked the students: 'Compared with the traditional lecture (such as in topics no 1 , no 2 or no 3), how much did you like the flipped lecture?' After this, survey question no 5 required the students to explain their reasons for their prior answer: 'Could you please give two reasons that justify your answer to question no 4 above?' Adding this open-ended question to the survey allowed us to offer insights not captured by the closed-ended questions. ${ }^{15}$ The students' responses to the survey question no 5 were read and grouped into categories manually. Each category was defined by identifying and grouping comments that shared the same central idea. ${ }^{16}$

15 Natalie L Sproull, Handbook of Research Methods: A Guide for Practitioners and Students in the Social Sciences (Scarecrow Press, $2^{\text {nd }}$ ed, 2002).

16 Kristin M Jackson and William M K Trochim, 'Concept Mapping as an Alternative Approach for the Analysis of Open-Ended Survey Responses' (2002) 5 Organizational Research Methods 307; Matthew B Miles and A Michael 
A total of 186 reasons were given by the students. Sixty per cent of those reasons shed positive light on the flipped lecture relative to the traditional lecture, 30 per cent shed negative light on the flipped lecture, and 10 per cent were considered neutral reasons. The high percentage of reasons in support of the flipped lecture was unexpected as it shows greater support for the flipped lecture than the support acknowledged by the students when asked to rate quantitatively the flipped and traditional lectures in other survey questions.

The most cited reason against the flipped lecture was poor learning (Figure 1). The complaints in this category emphasised the students' lack of focus or concentration when watching the videos, the lack of interaction between students and the lecturer as well as the short duration, and thus the more concise content, of the pre-recorded videos. The following quotations illustrate the students' perception under this category: "no sufficient communication with teachers in [the] video lectures'; 'the explanation is not as much as [in the] traditional class'; 'harder to concentrate'.

Other negative reasons, cited far less frequently, were IT-related problems with the videos ('Network connection for [Lecture no 4] is terrible'; 'Video loading problems'), heavier workload ('It raises students' workload to make tone[s] of preparation (heavier than normal preparation) before the lecture') and MCQ-related problems especially the fact that the quiz was graded and that not all the MCQs could be answered by watching the videos but required textbook reading instead ('The answers [to the] MCQs could rarely [be] found from [the] video lectures we should find [them] carefully from the textbook instead'; 'The main problem is the difficulty, the pressure of being graded and how the video did not have enough information to answer the MCQs correctly').

Figure 1

\section{Reasons Against the Flipped Lecture}

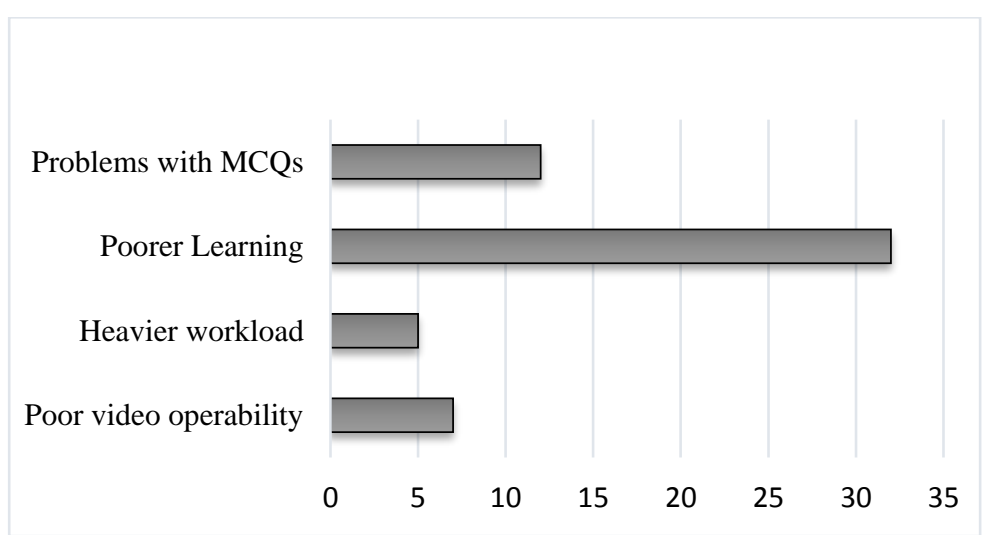

Huberman, Qualitative Data Analysis: An Expanded Sourcebook (Sage, $2^{\text {nd }}$ ed, 1994); David Silverman, Doing Qualitative Research: A Practical Handbook (Sage, 2005). 


\section{Figure 2}

\section{Reasons For the Flipped Lecture}

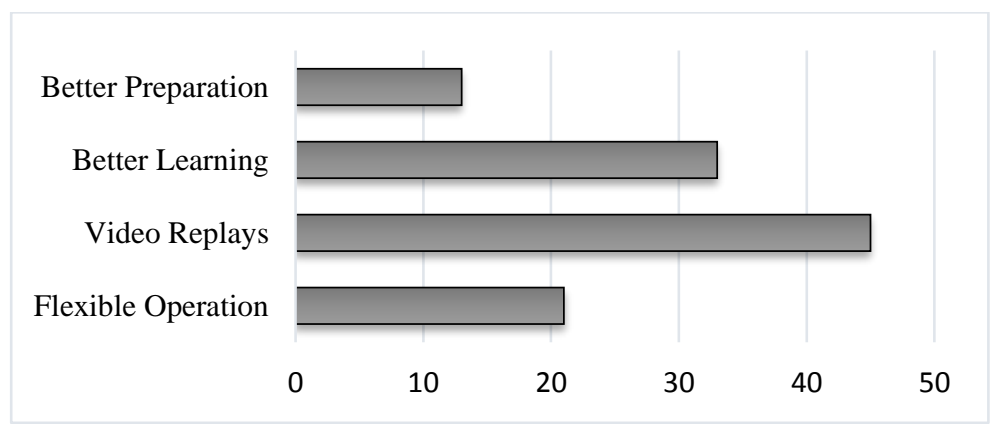

Fifty-nine per cent of the positive reasons cited by the students stressed the flexible access and operation of the videos, including the ability to replay the video (Figure 2). This latter category concentrated 45 per cent of all the positive reasons cited. The following quotations are illustrative: 'can watch more than one time'; 'In [the] traditional lecture, I may miss some points and may not be able to jot down all of them. Yet, using [the] flipped lecture, I can replay the main points'; 'it gives chances to [the] students to watch/listen to the lecture again as the lecturer may have spoken too fast'; 'you can replay the video if you miss some important information'.

Very importantly, the replay function in the videos was very often associated by the students with more clarity and better understanding of the topic: 'because I can watch [it] more than [one] time, [I] can understand the content more'; 'I was not used to listen[ing] to the lecturer's accent. If I could replay it, I could understand what he's saying', 'I can replay the video to understand more'; 'can replay [it] many times until I understand'.

Another positive reason given by the students was better learning. Reasons citing greater clarity in the explanations and better understanding of the lecture were again critical in this category. Moreover, a few students perceived the flipped lecture as providing them with greater motivation: 'The multimedia materials [are] more interesting than paper materials'; 'more motivation to learn'; 'more interesting'. In relation to better preparation, the students said that the video helped them to know what to study or revise for both seminars and examinations: 'I can review the video when I prepare for the final exam'; 'Prepare me better to work in the seminar'; 'A compulsory measure/effort to read/study before class'.

\section{RESULTS FROM THE COURSE ASSESSMENT}

Table 4 shows the mean grades from diverse course assessments, namely CP (class participation), GW (in-class group work) and FEQs (final exam questions). The total course assessment was composed of three GW seminars (10 per cent), two CP seminars (10 per cent), one essay assignment (30 per cent) and one closed-book final exam 
composed of four compulsory FEQs (50 per cent). For the sake of allowing t-test comparisons of students' performance, one GW, one $\mathrm{CP}$ and one FEQ evaluated a topic taught by means of the flipped lecture, whereas the rest of the course assessments evaluated topics delivered through the traditional lecture. The prefixes FL and TL denote that the topic under assessment was taught by means of the flipped lecture (FL) or by means of the traditional lecture (TL).

\section{Table 4}

Summary Statistics of Course Assessment Variables and T-tests

Table no. 4 - Summary Statistics of Course Assessment Variables and T-tests

\begin{tabular}{|c|c|c|c|c|c|c|c|}
\hline Variables & Obs & Mean & Std. Dev. & Min & Max & Obs & t-test(mean comparisons) \\
\hline FL_CP1 & 179 & 1.212 & 1.434 & 0 & 7 & 179 & FL_CP1 and TL_CP2 $=0$ \\
\hline TL_CP2 & 179 & 1.212 & 1.332 & 0 & 5 & & \\
\hline FL_GW1 & 177 & 6.960 & 0.884 & 0 & 8.5 & - & - \\
\hline TL_GW2 & 177 & 6.763 & 0.727 & 0 & 8 & 177 & FL_GW1 and TL_GW2 $=0.214^{* *}(2.489)$ \\
\hline TL_GW3 & 174 & 6.984 & 1.051 & 0 & 9 & 174 & FL_GW1 and TL_GW3 $=0$ \\
\hline TL_FEQ1 & 183 & 12.604 & 6.404 & 0 & 22.5 & 183 & TL_FEQ1 and FL_FEQ2 $=1.623^{* * *}(-2.922)$ \\
\hline FL_FEQ2 & 183 & 14.227 & 3.928 & 2.5 & 22 & & \\
\hline
\end{tabular}

T-test (means comparison) results, shown in Table 4, indicated that score levels were roughly the same across comparisons, except for the case of GW (FL_GW1 > TL_GW2; t-test = 2.489) and of the FEQs $($ FL_FEQ2 > TL_FEQ1; t-test $=-2.922)$ where the topic taught by means of the flipped lecture scored higher. As was the case in relation to the survey variables (Table 3), the students' gender or age did not affect the results meaningfully. But the GPA scores became again a relevant factor in the comparison of FEQ grades. The GPA average in our course grades sample used to categorise Low- and High-GPA students amounted to 3.08 points.

As shown in Table 5, whereas the group of High-GPA students obtained similar scores for TL_FEQ1 and FL_FEQ2 (14.728 < 15.239; t-test $=-0.751)$, the performance of Low-GPA students was significantly better when the question evaluated a topic taught through the flipped lecture (TL_FEQ1 $=10.456$ and TF_FEQ2 = 13.203; difference $=-2.747$; -test $=-3.390)$. Consistent with previous findings in this article, the use of the flipped lecture served to alleviate the needs of the weaker students, reducing by more than a half the gap in marks between Low- and High-GPA students (from -4.272 marks in TL_FEQ1 to -2.036 marks in FL_FEQ2). The fact that the degree of difficulty in the topics of FEQ1 and FEQ2 need not have been identical is a reason to be cautious when reading these results. Both FEQs were graded by the same teacher. 
Table 5

Differences in Assessment Outcomes by level of GPA

Table no. 5 - Differences in Assessment Outcomes bylevel of GPA

\begin{tabular}{|c|c|c|c|c|c|c|}
\hline \multirow[b]{2}{*}{ Variable } & \multirow{2}{*}{$\begin{array}{c}\text { Mean } \\
\text { (all obs) }\end{array}$} & \multicolumn{5}{|c|}{ GPA } \\
\hline & & Obs & $\begin{array}{l}\text { Low } \\
\text { (mean) }\end{array}$ & Obs & $\begin{array}{l}\text { High } \\
\text { (mean) }\end{array}$ & t-test \\
\hline TL_FEQ1 & 12.604 & 91 & 10.456 & 92 & 14.728 & $\begin{array}{c}-4.272^{\star * *} \\
(-4.775)\end{array}$ \\
\hline FL_FEQ2 & 14.227 & 91 & 13.203 & 92 & 15.239 & $\begin{array}{c}-2.036^{* * *} \\
(-3.620)\end{array}$ \\
\hline t-test & $\begin{array}{c}-1.623^{* * *} \\
(-2.922)\end{array}$ & & $\begin{array}{l}-2.747^{\star * *} \\
(-3.390)\end{array}$ & & $\begin{array}{c}-0.511 \\
(-0.751)\end{array}$ & \\
\hline
\end{tabular}

Note: ${ }^{* * *}$ denotes significance at $1 \%$ (T-test mean-comparison test).

\section{CONCLUSION}

Did the students prefer the flipped lecture over the traditional lecture? Did the flipped lecture prepare the students better to undertake deep-learning seminar tasks? The results from the survey indicated a very narrow margin in favour of the flipped lecture in terms of likeability and preparedness. When the students were asked to give a score to the flipped and traditional lectures separately, the flipped lecture scored higher yet without achieving statistical significance. Overall, these results seem to be at odds with the findings in the literature showing the flipped classroom as having a beneficial edge, ${ }^{17}$ but more consistent with studies where the flipped and the traditional lectures were found to be equally effective. ${ }^{18}$

However, this result did not hold across all the student groups in our sample. Perhaps the most valuable finding from this research has been that the group of Low-GPA students, on average, gave a

17 The studies that found a better performance in the flipped classroom include, among others, Stefanie P Ferreri and Shanna K O'Connor, 'Redesign of a Large Lecture Course into a Small-Group Learning Course' (2013) 77 American Journal of Pharmaceutical Education (Article 13); Michael Albert and Brian J Beatty 'Flipping the Classroom Applications to Curriculum Redesign for an Introduction to Management Course: Impact on Grades' (2014) 89 Journal of Education for Business 419; Jacqueline E McLaughlin et al, 'The Flipped Classroom: A Course Redesign to Foster Learning and Engagement in a Health Professions School' (2014) 89 Academic Medicine 236; Adam Butt, 'Student Views on the Use of a Flipped Classroom Approach: Evidence from Australia' (2014) 6(1) Business Education and Accreditation 33.

18 The studies that found the flipped and traditional classroom to be equally effective include, among others, Jeremy F Strayer, 'How Learning in an Inverted Classroom Influences Cooperation, Innovation and Task Orientation' (2012) 15 Learning Environments Research 171; Sandi Findlay-Thompson and Peter Mombourquette, 'Evaluation of a Flipped Classroom in an Undergraduate Business Course' (2014) 6(1) Business Education and Accreditation 63; Heng Ngee Mok, 'Teaching Tip: The Flipped Classroom' (2014) 25(1) Journal of Information Systems Education 7. 
significantly higher score to the flipped lecture, and they did so consistently across most of the metrics used in this study. This evidence sheds light on the flipped lecture's ability to assist the group of students who need the most support in learning. The composition of our classrooms has long been characterised by students showing different levels of ability, and educational interventions capable of providing academic support to the weaker or 'at risk' students achieve a legitimate tenet. They help students complete their courses more successfully, with crucial implications to their career prospects and to the school's student retention levels. ${ }^{19}$ It is noted, however, that the positive contribution of the flipped lecture to Low-GPA students found in this study appears to contradict findings from prior research.

In the work of Le et al, live lectures were delivered and videorecorded during class in a calculus course. The students were allowed to attend the live lectures and/or watch online the 'live lecture' videorecording. The authors found that those students who complemented their class attendance with online viewing, and those who used the video-control features the most (video pause and seek bar function), performed the poorest in the course. Two explanations for this negative correlation between video usage and students' performance were given. First, the students who tended to use the pause feature the most were students who adopted a superficial strategy to study calculus - in the sense that students made minimum effort to pass the course and studied by focusing on the concrete aspects of tasks rather than on their meaning, including the memorisation of concepts. Second, memorisation was not an adequate strategy to study complex issues such as calculus.

In the study of $\mathrm{Lu}$ and Lemonde, ${ }^{20}$ the students registered for a health science statistics course were split into two groups, one group being taught by video-lectures and the other group by face-to-face lectures. The results for each group were compared, and the authors found no statistically significant difference between the groups when the students were high performers. When the students were low performers, however, video-lectures proved significantly less effective than live lectures. In order to make sense of this outcome, the authors advanced a number of explanations.

They suggested (similar to Le et al) that video-lectures are less able to assist lower-performing students when the course content involves a higher level of cognitive skills. Moreover, the authors saw several benefits for lower-performing students in the face-to-face lectures. The latter provide students with a better structure on how to study the course content (due to regular physical meetings in class) and, in so doing, face-to-face lectures force upon those students greater study discipline and focus. In addition, lower-performing students are able to interact with the instructor in live lectures in order

19 See generally Landrum, above n 12. See also Vincent Robert Johnson, 'Audiovisual Enhancement of Classroom Teaching: A Primer for Law Professors’ (1987) 37 Journal of Legal Education 97.

20 $\mathrm{Lu}$ and Lemonde, above $\mathrm{n} 3$. 
to clarify questions or doubts, and this interaction - which is absent in video-lectures - is particularly valuable when the topic of study is complex and requires a great deal of abstract thinking.

Our study yielded similar results to Le et al insomuch as it was found that Low-GPA students expressed greater satisfaction with the video-lectures and were more inclined to use the video-functions. Consistent with a positive correlation between GPA levels and assessment grades, Low-GPA students also performed worse than High-GPA students in the final exam. Unlike the findings in Le et al and in Lu and Lemonde, however, our study found that the flipped lecture was associated with a significantly narrower gap between the scores obtained by Low- and High-GPA students. Hence, the claim that the flipped lecture proved of particular benefit to Low-GPA students. Different reasons may explain this dissenting result.

Unlike Le et al and $\mathrm{Lu}$ and Lemonde, the video-lectures in our study were designed within the frame of the flipped classroom model. As such, the purpose of the videos was to convey to our students no more than the basic level of cognitive skills, namely acquiring the essential knowledge and understanding of the lecture topic. The videos were not meant to address more complex skills. Skills of higher level, namely the application of the law to a concrete problem, were taught separately in two-hour live seminars. Bloom's taxonomy, often cited in this type of research, is guided by a pyramid of cognitive skills which are built incrementally. The sound acquisition of basic skills (knowledge and comprehension) located at the base of the pyramid is expected to prepare students to develop skills higher up in the pyramid, among them being the ability to apply the law to resolve legal problems. This has been the rationale guiding the flipped lecture.

Moreover, the frame within which the flipped lecture operated, unlike the video-lecture design in $\mathrm{Lu}$ and Lemonde, allowed for a great deal of live interaction between the students and the instructor. The flipped lecture was not conceived as a purely e-learning experience but rather introduced e-learning as part of a blended learning approach. ${ }^{21}$ The online quiz exercise was a graded task complemented, subsequently, with a one-hour oral feedback session. Seminar classes were delivered on a face-to-face basis and directed at smaller groups of students. It is suggested that all these elements put together may have minimised potential problems of study discipline and of teacher-student interaction in the group of Low-GPA students.

Evidently, the content of a course on company law differs from that imparted in a course on calculus or statistics. The retention of key facts and concepts as well as the understanding of legal definitions and arguments are basic, yet important skills in the law toolkit. ${ }^{22}$

21 See, eg, Stephen Colbran and Anthony Gilding, 'E-Learning in Australian Law Schools' (2013) 23 Legal Education Review 201 (reporting an ample adoption of blended methods of instructions in Australian Law Schools).

22 See, eg, Bahnson and Olejnikova, above n 5 (evaluating LLM students' rate of retention in a legal research course; the authors found no difference in the rate of 
Without these skills, problem-solving and critical thinking are more difficult to develop. The ability to take notes, self-pace, and listen anew to the whole set of facts, definitions and explanations, may have allowed Low-GPA students to keep up and get ready to enter the next phase of learning. As reflected in the results from the student survey, Low-GPA students felt that the video-lectures had assisted them well in this effort ('Preparedness' variable mean $=3.884$ ). Also, in the survey's open-ended question the students associated the operability of video-lectures — the ability to pause or replay the videos — with better learning in terms of greater clarity and understanding of the content of the lecture.

It is noted that when evaluating the performance of the flipped lecture, this latter was taken to constitute a single bundle of tasks or single tool, and no explicit distinction was made between its different components. In only one survey question were the students asked to rate separately, from 1 to 10 points, the videos and the quiz. The videos were rated higher than the quiz and the difference was statistically significant. Here again, the difference in perception seems to find a source in the group of Low-GPA students. The evidence indicates that the video component of the flipped lecture played a preponderant role in forming perceptions. The preponderant role of the pre-recorded videos was also found among the reasons stated by the students for or against the flipped lecture. Those reasons focused largely on different aspects of the video-lecture and paid much less attention to the MCQs and oral feedback session. Watching the video repeatedly was cited the most frequently by the students as an advantage of the flipped lecture.

Unlike other studies found in the literature, the absence of interaction, a characteristic of video watching, did not weigh heavily in the preferences of our students. In the study of Schreiber, Fukuta and Gordon, one group of students was taught by means of videolectures and another group by means of face-to-face lectures. No significant difference was found in the performance of the students between these two groups. The students stated in the survey evaluation that they had enjoyed the convenience of the videos and their ability to stop, rewind and replay them. But since the students found the video-lecture less engaging, they ultimately indicated a clear preference for the face-to-face lecture format. ${ }^{23}$ Findings from other studies, such as Jensen, also mirrored the special value that some students give to class interaction and its benefits. ${ }^{24}$ In contrast with this result, our students gave preponderance to the video-operability over the absence of interaction. This finding may result from traits of our students from local uses and culture which make the students highly oriented to technology use and less inclined towards in-class interaction with the teacher.

retention of legal concepts between a group of students taught by a live lecture and another group taught using a video recorded module).

23 Schreiber, Fukuta and Gordon, above $\mathrm{n} 2$.

24 Scott A Jensen, 'In-Class Versus Online Video Lectures: Similar Learning Outcomes, But a Preference for In-Class' (2011) 38 Teaching of Psychology 298. 
Despite their lower preference, the students still rated the online quiz task reasonably high (6.041 out of 10 points). Although the students' perceptions were captivated more by the flipped lecture's video component, the value of the quiz component to the students' preparedness should not be underestimated. The online quiz was meant to function, at least in part, as a reading quiz. The literature has shown that reading quizzes have a positive impact on students' preparation and performance. ${ }^{25}$ In the study of Geiger and Bostow one half of the class was randomly assigned reading quizzes whereas the other half was assigned no quizzes. The authors found that the quiz group performed approximately one letter grade higher in the exam tests. ${ }^{26}$ In the study of Johnson and Kiviniemi, the students sat exam tests that included questions that were covered and not covered by reading quizzes. The students' performance was significantly better in those questions covered by the reading quizzes. ${ }^{27}$

While feedback has been viewed to be central to learners, ${ }^{28}$ some evidence suggests that automated written feedback in MCQs has been insufficient to meet the students' preferences ${ }^{29}$ or improve their performance. ${ }^{30}$ Taking this evidence into account, the flipped lecture added a face-to-face feedback session component. Voluntary answers to the survey's open-ended question showed only little awareness by our students of the positive learning properties of the quiz and oral feedback even when the rate of attendance to the feedback session (73.6 per cent) was reasonably high.

One of the obstacles that may have reduced the effectiveness of the live feedback session was the fact that the lecture hall, where such sessions took place, had fixed seats. This physical setting prevented the session from being organised in a way that fostered group work or from achieving a more fluent peer-to-peer and student-teacher

25 Rodger Narloch, Calvin P Garbin and Kimberly D Turnage, 'Benefits of Prelecture Quizzes' (2006) 33 Teaching of Psychology 109; Robert B Graham, 'Unannounced Quizzes Raise Test Scores Selectively for Mid-Range Students' (1999) 26 Teaching of Psychology 271; Thomas Brothen and Cathrine Wambach, 'The Value of Time Limits on Internet Quizzes' (2004) 31 Teaching of Psychology 62; Regan A R Gurung, 'Pedagogical Aids and Student Performance' (2003) 30 Teaching of Psychology 92; Tracey E Ryan, 'Motivating Novice Students to Read their Textbooks' (2006) 33 Journal of Instructional Psychology 135; Monseau, above n 1.

26 O Glenn Geiger and Darrel E Bostow, 'Contingency-Managed College Instruction: Effects of Weekly Quizzes on Performance on Examination' (1976) 39 Psychological Reports 707; see also John L Dobson, 'The Use of Formative Online Quizzes to Enhance Class Preparation and Scores on Summative Exams' (2008) 32 Advances in Physiology Education 297.

27 Bethany C Johnson and Marc T Kiviniemi, 'The Effect of Online Chapter Quizzes on Exam Performance in an Undergraduate Social Psychology Course' (2009) 36 Teaching of Psychology 33.

28 David Boud and Elizabeth Molloy, 'What is the Problem with Feedback?' in David Boud and Elizabeth Molloy (eds), Feedback in Higher and Professional Education (Routledge, 2013) 1.

29 Félix E Mezzanotte, "Use of "Reading Quizzes" to Foster Learning: Evidence from Teaching Company Law in Business Programmes' (2017) 51 The Law Teacher 349.

30 Wieling and Hofman, above n 6. 
interaction. A better outcome could have taken place if the one-hour feedback session was organised together with - as a one-hour extension to - the weekly two-hour seminar class which takes place in a more suitable setting for student engagement and interaction. But this alternative design was precluded in our study by a time-rigid course schedule.

Further research in teaching company law may look at the effects of the video-lecture utilised as a complement to the face-to-face lecture, instead of as a substitute. This model may, to an extent, match our students' preferences well, especially Low-GPA students, as they have shown a higher interest in the video component of the flipped lecture but less enthusiasm for the online quiz and oral feedback session components. Although this blending learning design has been tested in the past in diverse settings, such as Le et al in calculus courses, it would be insightful to evaluate how the performance of Low-GPA student may differ from prior studies in the distinct context of law courses. 